University of South Carolina

Scholar Commons

Fall $10-5-2020$

\title{
Using the World Café Methodology to Support Community-centric Research and Practice in Library and Information Science
}

\author{
Vanessa Kitzie \\ University of South Carolina, kitzie@mailbox.sc.edu \\ Jocelyn Pettigrew \\ Richland Library, JPettigrew@RichlandLibrary.com \\ Travis L. Wagner \\ University of South Carolina - Columbia \\ Nick Vera \\ University of South Carolina - Columbia
}

Follow this and additional works at: https://scholarcommons.sc.edu/libsci_facpub

Part of the Gender, Race, Sexuality, and Ethnicity in Communication Commons, Health Communication Commons, and the Health Sciences and Medical Librarianship Commons

\section{Publication Info}

Preprint version Library \& Information Science Research, Fall 2020.

(c) Library \& Information Science Research 2020, Elsevier

This Article is brought to you by the Information Science, School of at Scholar Commons. It has been accepted for inclusion in Faculty Publications by an authorized administrator of Scholar Commons. For more information, please contact digres@mailbox.sc.edu. 


\section{Introduction}

The World Café (TWC) methodology facilitates community conversations that foster participantled collective change. Its core principles align with the LIS field, which has become increasingly participatory and community-centric. The authors report on a case study applying TWC to a community forum between lesbian, gay, bisexual, transgender, queer, intersex, and asexual (LGBTQIA+) community leaders, librarians, and paraprofessionals from [name removed for blind review]. The subject of the forum was how public libraries could assist local LGBTQ+ communities in addressing their health questions and concerns. Findings indicate that while TWC opened up new avenues and offered promising future directions for collaborations between LGBTQIA+ communities and public libraries, it also failed to consider structural inequalities and facilitate social change. Based on these weaknesses, the authors conclude with implications for revising the methodology to address these issues by adopting reflexive and intersectional methods.

\section{What is TWC?}

TWC is a popular and internationally recognized participatory methodology that brings together large groups of people to discuss relevant issues in academic, organizational, and community settings (Brown \& Isaacs, 2005; Jorgenson \& Steier, 2013; Lorenzetti, Azulai, \& Walsh, 2016). It is a form of action research: a broader research philosophy and methodology that develops collective knowledge among individuals and communities to address shared problems (Reason \& Bradbury, 2001). What differentiates TWC from other forms of action research is its ability to foster conversation among large groups of people by adopting design principles establishing a "third place" where participants engage in small-table conversations (Brown, 2001; Brown \& Isaacs, 2005). 
TWC also is unique in how it structures these conversations. Specifically, TWC conversations constitute an "innovative stand-alone methodology for dialogic inquiry" (Brown, 2001, p. iii) with their underlying philosophy, principles, guidelines, and procedures (Lorenzetti et al., 2016). Here, "dialogic inquiry" represents the conversational processes through which the methodology encourages participants to generate ideas of relevance to their organizations and communities on which they wish to collaborate (Bushe \& Paranjpey, 2015). Dialogic inquiry is a bottom-up process where the researcher does not "diagnose" communities or organizations by comparing them to an ideal standard, but instead provides an environment with enabling conditions for participants to identify common interests and think about future steps (Bushe \& Marshak, 2009). Therefore, TWC most closely aligns with a constructivist metatheoretical stance, which envisions people's worldviews as intersubjectively produced through conversations (Aldred, 2009; van der Haar \& Hosking, 2004).

The standard format for TWC consists of conversational rounds, 20 to 30 minutes each, between small tables of 4 to 5 people. The originators of this methodology suggest using tablecloths, vases with flowers, and light music to convey a café like atmosphere, as well as establishing café etiquette that facilitates open discussion and respect. Butcher paper may be placed on the tables with a cup for markers to encourage participants to write down emerging ideas, drawings, and notes, thus facilitating multiple forms of participation. A café host or hosts oversee TWC and are the project leaders. "Host" is used instead of "facilitator," as creators of the methodology contend that facilitating can reduce the quality of conversations by driving them as opposed to letting participants talk. Instead, the café-like environment and dialogic strategies used should in themselves enable conversation (Bushe \& Marshak, 2009). These dialogic strategies include asking questions that elicit "positive, constructive responses" (Aldred, 2009, p. 
57), such as, "What question, if answered, could make the greatest difference to the future of the situation we're exploring here?" (Brown \& Isaacs, 2005, p. 279). Participants spend 20-30 minutes discussing each question, then switch tables. One person remains at each table and functions as a table host. Their role is to welcome newcomers to the table, summarize the last conversational round, invite new conversation, and take notes. Hosts also encourage participants to integrate discussion from prior rounds into the current table's discussion. TWC can last for a few hours to multiple days. Following conversational rounds, the café hosts bring everyone back for a broad group discussion that summarizes key ideas and addresses the next steps (Brown, 2001; Brown \& Isaacs, 2005; Slocum, 2003; Steier, Brown, \& Mesquita da Silva, 2015).

Although creators of this methodology do not explicitly specify how researchers should record TWC data, studies applying this methodology use participant notes as key data sources, supplemented by other methods including audio-recordings and questionnaire responses (Fouche \& Light, 2010; Noonan et al., 2018; Terry, Raithby, Cutter, \& Murphy, 2015). Data analysis methods are also unspecified by the creators, but one can presume that the analysis of TWC data is primarily qualitative, given the textual nature of the data collected.

Since the purpose of TWC is to achieve positive collective change (Aldred, 2009), it is unsurprising that studies use it when examining organizations and communities as their units of analysis. Example applications include studies on organizational development (Bushe \& Marshak, 2009), community health services (Noonan et al., 2018), and higher education (Estacio \& Karic, 2016). Businesses and NGOs (Brown \& Isaacs, 2005) have also used the methodology. However, this literature is "fragmented" (Aldred, 2009, p. 57) because most work assesses TWC as a data collection method within a particular context, rather than exploring its effectiveness as a research methodology (Aldred, 2009; Lorenzetti et al., 2016). 
Advantages of TWC include accommodating 12 or more participants at one time and dynamically engaging them in the research process by giving them a sense of ownership over this process and the action steps derived from it (Abildgaard, Løvseth, Ala-laurinaho, \& Nielsen, 2018; Estacio \& Karic, 2016; Nielsen \& Randall, 2012; Tafvelin, Schwarz, \& Nielsen, 2019). TWC also can encourage democratic participation among people of different social statures by temporarily suspending power dynamics within Café spaces (Brown \& Isaacs, 2005; Carson, 2011; Fouche \& Light, 2010; Goldberg, Pasher, \& Levin-Sagi, 2006; Jorgenson \& Steier, 2013). In this way, TWC aligns with certain tenants of liberatory praxis by fostering critical dialog and education among diverse groups in ways that can lead to collective change (Aldred, 2009; Freire, 1970). This alignment occurs because TWC focuses on community as its unit of analysis; in other words, the purpose of TWC is to advance the good of a community rather than an individual or particular group (Carson, 2011; Lorenzetti et al., 2016; Thunberg, 2011).

\section{How TWC can advance LIS theory and practice}

Specific characteristics of TWC can align with and advance LIS research and practice in the following ways: refuting deficit frameworks, fostering information communities, and supporting social-justice-oriented praxis. Deficit frameworks presume that individuals or communities experience adversity because they cannot enact change (Craig, 2007). A critical way that LIS research and practice evoke these frameworks is by assuming that people have information needs because they lack capacity such as literacy skills or access to resources, to address these needs. This lack of capacity must be "corrected" via research and practice-based interventions (Frohmann, 1992; Julien, 1999; Olsson, 2005).

The emergent use of a constructivist metatheoretical orientation in LIS vis-à-vis metatheories, theories, and concepts such as sense-making (Dervin, 1999), information practices 
(Savolainen, 2008), information worlds (Jaeger \& Burnett, 2010), and information marginalization (Gibson \& Martin, 2019) counter deficit-based thinking by demonstrating how individuals and communities function as experts within their particular information worlds (see also Ocepek, 2017) and act despite existing structural barriers. TWC provides a complementary methodological choice for researchers and especially practitioners (Aldred, 2009) to counter deficit frameworks because they allow participants to define problems and solutions, rather than having them imposed by the researcher(s).

TWC also is advantageous because it employs community, a concept central to LIS research and practice, as its unit of analysis. Examples of how LIS centers community include practice-oriented models framing libraries as participatory networks where communities can come together to converse (Lankes, Silverstein, \& Nicholson, 2007); funding agencies, which are offering specific community-centric tracks, such as the Institute for Museum and Library Service's (IMLS) community catalyst initiative (Institute for Museum and Library Services, n.d.); and research focusing what different communities $d o$ with information, often with a specific focus on underserved, disenfranchised, vulnerable, or otherwise marginalized groups (e.g., Chatman, 1996, 1999; Fisher, Durrance, \& Hinton, 2004; Gibson \& Martin, 2019; Greyson, 2017; Kitzie, 2019; Lloyd, Anne Kennan, Thompson, \& Qayyum, 2013; Westbrook, 2009). While these works do not use the term explicitly, many of the populations studied can be called "information communities," as they collectively mobilize resources to address their questions and concerns (Durrance, 2001; Fisher \& Bishop, 2015). TWC can strengthen information communities by allowing members to collaborate and get a sense of each other's strengths. TWC also can help connect members with information providers outside of their 
immediate communities who might be able to facilitate information flow, such as by identifying emerging technologies to enhance information sharing.

Finally, TWC's alignment with elements of liberatory praxis supports the field's recognized potential for social justice. By engaging TWC within libraries, librarians can support critical thinking and action that problematizes knowledge production and information representation for a specific community. For example, a TWC bringing together public services librarians and LGBTQIA+ communities could interrogate how library catalogs privilege heterosexual and cisgender identities and provide communities with both the dialogic tools and reflective space to think through possibilities for disrupting these ideals (example, sans application of TWC, from Drabinski, 2013). Whereas previous work theorizes the value of dialogue in challenging systemic presumptions, TWC makes dialogue a preeminent feature of implementation.

There is also the potential to fold TWC into a social-justice-oriented, and communitycentric LIS curriculum as part of a service-learning component. Students could volunteer for TWC and learn from communities about the potential roles for librarians to leverage their existing knowledge and information-related skills. Such applications of service-learning with a social justice component prove generative across LIS curriculum, whether in archival work (Wagner \& Lewis, 2018) or academic librarianship (Stark, 2017).

\section{Case study: Applying TWC to examine public library services to LGBTQIA+ communities for health information}

In November 2019, the authors used TWC to structure a community forum at [name removed for blind review] in [name removed for blind review] with 16 LGBTQIA+ community leaders, 14 librarians \& paraprofessionals, 6 volunteers, and 2 research leads. The forum is part of a larger 
research project funded by IMLS and received Institutional Review Board approval from [name removed for blind review] (approval number Pro0008587). Prior to the forum, the authors conducted individual semi-structured interviews with 30 LGBTQIA+ community leaders from [name removed for blind review] about their community's health questions and concerns and how they addressed them. Informed by definitions for community established in the literature (Hillary, 1995), the authors developed and emailed a contact list of over 100 statewide LGBTQIA+ communities and affinity groups, asking them to self-nominate leaders for interviews. Following interviews, the authors invited leaders to participate in TWC; the 16 who participated were self-selected from this initial participant pool. The authors also worked with the [names removed for blind review] libraries to recruit 14 librarians and paraprofessionals from across the state. Participants were required to have a history of working with LGBTQIA+ populations. Finally, the authors recruited six volunteers to help plan and implement TWC. Participants received travel stipends upon request, as well as $\$ 75$ honoraria for community leaders and \$100 honoraria for table hosts. Librarians and paraprofessionals could not receive honoraria due to workplace stipulations.

TWC lasted a half-day with breakfast and lunch provided. It took place in [name removed for blind review]'s meeting room, which has a capacity for 40-60 people. Ahead of time, the authors decorated the room per TWC guidelines - arranging round tables with four chairs each, covering the tables with tablecloths and butcher paper, and placing vases with flowers and cups with makers on top of each table. Jazz music played, establishing a café-like ambiance. Participants received a folder containing printouts of TWC discussion questions and format, an executive summary of interview findings, an informed consent form, a Brave Spaces (Arao \& Clemens, 2013) handout, a feedback form, and the lead researcher's contact 
information. The authors selected table hosts ahead of time - a mixture of community leaders, librarians, and paraprofessionals - and provided them with 30 minutes of in-person training prior to the forum. The authors called the forum the "Community Knowledge Café" to reflect the assumption that the people in the room already had the knowledge and information-related skills to address the health questions and concerns of LGBTQIA+ communities.

[Insert Figure 1 here. Caption: Image of TWC at Public Library]

The two lead researchers, or Café hosts, opened the forum by summarizing the critical situation that brought participants there: [name removed for blind review] LGBTQIA+ communities face challenges addressing their health questions and concerns. The Café hosts then presented a summary of community-specific findings related to this situation informed by semistructured interviews. They followed this summary with an overview of the TWC principles and etiquette, emphasizing the importance of participant confidentiality. Participants supplemented this etiquette by engaging in a group-wide discussion addressing the question: "Think of a time when you felt heard or listened to. What were the conditions that allowed that to happen?"

TWC then proceeded in three twenty-minute discussion rounds. At the beginning of each round, the Café hosts posed a question for discussion. Following the round, the Café hosts gave participants a few minutes to write down a key idea from their table's discussion on a Post-It that they would bring to their next table. In subsequent rounds, table hosts would welcome new participants and summarize their prior table's conversation. Participants would then share their main idea. These strategies facilitated TWC principles ensuring everyone's participation and cross-pollination of ideas. Then, tables would engage in discussion related to the next question, repeating the process for three conversational rounds. Informed by TWC principles, the three questions were: 1) What question, which, if answered, could make a difference to the situation 
bringing us here today?; 2) What is the next level of thinking needed to answer the question your current table has posed?; 3) If our success was guaranteed, what steps might we take next?

Volunteers wrote questions generated during the first round on Flipboard paper.

Following the last round, participants took their ideas written on Post-Its and stuck them on Flipboard paper with the question corresponding to that idea. They then took a "listening" tour: volunteers hung up the butcher paper, on which participants had been jotting ideas, notes, and doodles, around the room alongside the Flipboard paper. These two methods - the idea cluster and gallery tour - were informed by TWC principles related to identifying collective ideas and ways to move forward (Brown \& Isaacs, 2005). Following the three rounds and listening tour, participants reconvened for a large-group discussion to summarize key findings and discuss the next steps for action. After the forum concluded, LGBTQIA+ community leaders had use of the meeting room for the rest of the day to network sans the presence of researchers, librarians, and paraprofessionals.

[Insert Figure 2 here. Caption: Flipboard paper with a table's first-round question. Post-Its contain participant summaries of main ideas addressing this question.]

[Insert Figure 3 here. Caption: Detail from butcher paper on each table that participants used to take notes.]

\section{Reflecting on TWC case study: What worked and what did not}

Findings from applying TWC to the community forum confirmed several methodological advantages discussed above. Participants reported that TWC fostered "good ideas that are actionable," as reported by one LGBTQIA + community leader in their feedback (Brown \& Isaacs, 2005). TWC also allowed librarian and paraprofessional participants to question deficitbased service frameworks (Frohmann, 1992; Julien, 1999; Olsson, 2005), and instead focus on 
the knowledge and information they lacked when engaging with these communities. For example, one librarian/paraprofessional called the forum in their feedback:

eye-opening [...] I learned about challenges that I had never considered. It made LGBTQ inclusion a less 'abstract' issue and now I could put many names and faces to it and motivated me to try to be a better advocate.

This mention of advocacy also highlights TWC's potential to foster critical, liberatory, and social-justice centered praxis among librarians and paraprofessionals (Aldred, 2009; Freire, 1970). Librarians/paraprofessionals further exemplified this potential by questioning how public libraries might oppress LGBTQIA+ communities. For instance, one librarian/paraprofessional stated in their feedback that the most important thing they learned was that "the institution of the library may be another institution that LGBTQ+ folks are wary of."

LGBTQIA+ leaders also reported benefitting from TWC. Specifically, TWC appeared to strengthen their information communities by enabling social networking and connectivity with other leaders (Durrance, 2001; Fisher \& Bishop, 2015) as illustrated by the following leader feedback:

My biggest takeway [sic] from the forum was that even in State, there is a great number of organizations and individuals who do great work and are not aware of each other, despite the fact that they may be in relatively close proximity and have similar missions. This networking was not exclusive to within LGBTQIA+ communities, but also included relationships between them and public libraries. For example, during the broad group discussion, a librarian/paraprofessional asked leaders to share with their members that the person could provide notary services and process paperwork for those who wished to change their names. One of the table hosts (an LGBTQIA+ community leader) then stated that the primary mission of his 
community is to provide aid and resources for name change services. This exchange led to a new opportunity for the librarian/paraprofessional and leader to provide LGBTQIA+ communities with name change services by harnessing their collective knowledge and engaging in information sharing among community networks - two other facets of information communities (Durrance, 2001; Fisher \& Bishop, 2015).

However, TWC had several methodological weaknesses: failing to account for power imbalances, suppressing dissent, and lacking reflexivity. These weaknesses emanate from a central claim of TWC that envisions conversation as occurring in a vacuum from the external world, in which power differentials are temporarily suspended (Brown \& Isaacs, 2005). This claim does not align with TWC's metatheoretical roots in social constructivism because it envisions TWC space as devoid of broader social and cultural context. This misalignment between philosophical claims and methods employed has detrimental consequences for outcomes of TWC research and this case study in particular.

First, TWC does not account for power imbalances between researchers and participants. Specifically, TWC adopts what appears to be a universalist approach to community empowerment by presuming that researchers can define the relevant stakeholders necessary to confront a particular topic. For instance, the authors assumed that public libraries could meet some of the challenges LGBTQIA+ communities faced when addressing their health questions and concerns. The fact that the authors' research is supported by IMLS, which has an organizational agenda to support and advance the work of libraries, archives, and museums, bolsters this assumption. Informed by this assumption, the forum discussions did not explore topics explicitly questioning or refuting the relevance of these institutions in the lives of LGBTQIA+ communities. Further, the forum reified the deficit framing that TWC purports to 
reject by assuming that LGBTQIA+ communities lacked the capacity to address their health questions and concerns, which could only be given to them by public libraries' services, spaces, and collections (Aldred, 2009; Frohmann, 1992; Julien, 1999; Olsson, 2005).

Centering public libraries in this space inadvertently cut LGBTQIA+ community leaders off from other stakeholders whom should have been included in this discussion. Based on the authors' observations during and after the forum, leaders were interested in developing relationships with medical professionals. Including medical professionals in a follow-up TWC was a suggestion made by leaders, librarians, paraprofessionals, and table hosts in post-forum feedback. Not including this essential group of stakeholders in the initial TWC was a mistake the authors made made based on not interrogating more critically the underlying assumptions inherent to the research design.

This discussion highlights why TWC is not participatory action research (PAR). While PAR has communities define their needs and solutions via a "bottom-up" process requiring the researchers to cede control of their project, TWC imposes these needs and solutions on communities. This argument aligns with the existing critique of TWC's empowerment rhetoric as encompassing a "weak" form of constructivism where there is a "right" or "dominant" perspective, rather than a "strong" form, which envisions empowerment as subject to highly contextualized, community-based definitions (Aldred, 2009; Craig, 2007).

A second, related issue concerns TWC's framing of discussion questions in favorable terms, borrowed from tenants of positive psychology (Aldred, 2009). Specifically, writings describing TWC methodology discourage questions that focus on adverse effects and instead encourage rewriting these questions to focus on positive outcomes. The issue with this framing is its potential to suppress dissent by making participants feel that articulating their challenges is off- 
topic (Aldred, 2009). The authors observed participants adopting this rhetorical shift in the forum by redirecting others' direct challenges to structural forms of oppression into positive "solutions." During the broad group discussion, an LGBTQIA+ community leader brought up that they and members of their community could lose their jobs due to being LGBTQIA+ because the county where they resided did not have anti-discrimination policies. A librarian/paraprofessional immediately reworked this claim into a positive, stating that LGBTQIA+ people who worked at their library could not lose their jobs for these reasons. This comment ultimately failed to address the realities that the leader and their community did not reside in the same progressive urban hub as the library, nor did they necessarily have the economic and educational capital to work at this library. Further, the notion of speaking up and participating is itself a product of heteronormative discourses, which presume that there do not exist ways of participating "aside from the vocal sounds and hand movements" historically marked as speaking up (Lovaas, 2003, p. 88). Leaders may have made agentic and deliberate choices not to speak, but instead use forms of communication not captured by the TWC methodology, such as protecting community members' identities and issues via purposeful silence or expressing concern via bodily actions, such as shaking one's head.

This last example also illustrates a final weakness of TWC: its lack of reflexivity, or an individual's awareness of how their experiences and identities shape their perceptions. Although TWC claims to establish reflexivity as part of its underlying philosophy, its methods do not reflect this claim since there exists no specific design process to facilitate reflexivity (Lorenzetti et al., 2016). As a result of the authors not being more intentional about their positionality as researchers, for example, they did not see how TWC could reinforce deficit framing because they took its claims at rejecting such framing at face value. Librarians/paraprofessionals also 
exhibited a lack of reflexivity when engaging with LGBTQIA+ community leaders. For example, during the large-group discussion, a librarian/paraprofessional stated that in their role, they did not care who was asking them for information; they would give the same services to an LGBTQIA+ person that they would give to anyone else. Several leaders expressed concerns with this sentiment, stating that librarians/paraprofessionals who did not acknowledge their LGBTQIA+ identities could potentially give them irrelevant and dangerous health-related information. Similar to the authors' blind spots as researchers, some librarians/paraprofessionals appeared to fall back on what they considered to be a neutral vantage point. This vantage point is dangerous because it is not neutral; rather, it reifies existing structural and systemic inequalities that oppress LGBTQIA+ communities (Gibson et al., 2017).

As evidenced by this discussion, while TWC has the potential to advance community-centric LIS research and practice, its application must be taken with care as some of its underlying philosophies and methods do not align with the constructivist and justice-oriented approaches it claims to take (Aldred, 2009; Lorenzetti et al., 2016).

\section{Lessons Learned}

To counteract some of the power imbalances inherent to TWC, the authors made several methods-based choices that they will extend into future work and can be adopted by other LIS researchers and practitioners when using TWC within their communities. The first is to continue using established networks for recruitment, particularly for LGBTQIA+ community leaders who can constitute a hard-to-reach population (Gahagan \& Colpitts, 2017). Interviewing these leaders ahead of time allowed the authors to understand some of the structural challenges these communities faced. In the future, the authors will move beyond presenting interview findings at 
the beginning of TWC to critically integrating these findings into the discussion questions posed during the forums, even if these questions are not "positive" in nature.

Second, and related, is to continue to recruit librarians and paraprofessionals who have experience working with LGBTQIA+ populations or who are LGBTQIA+ themselves, particularly those with intersectional experiences of social difference. This strategy will encourage deeper reflexivity among participants with a diversity of experiences. The authors will also continue to address systemic barriers to participation. For LGBTQIA+ populations this means providing: an accessible location; single-stall bathrooms; remuneration, food, and childcare; locations that reduce their hypervisibility; and culturally sensitive identity signifiers, such as pronoun stickers. In the future, the authors will also seek alternative ways to compensate librarian/paraprofessional participants whose workplaces do not permit them to accept honoraria. The authors will also continue to establish a safe space during TWC by supplementing methodological etiquette with Brave Space (Arao \& Clemens, 2013) and participant-generated criteria. Finally, the authors will continue to cede some control back to LGBTQIA+ participants by giving them time after TWC to use the space for networking sans researcher, librarian, and paraprofessional presence. This action allows community leaders to discuss how to act on TWC ideas in a way that is contextually relevant for them, rather than sanctioned by the organizational interests of researchers and public libraries.

Following the authors' case study and informed by prior critiques (Aldred, 2009; Lorenzetti et al., 2016), there are some areas for improvement in future TWCs. First, the authors will extend data collection to capture better reflexivity. The two lead researchers for this project have been keeping reflexivity journals. They will code one another's journals and use the findings to identify areas lacking reflexivity in the current TWC structure. For instance, it was a fortunate 
coincidence that the lead researcher did not schedule the November forum on Transgender Day of Remembrance (November 20), which she did not consider given her identity as a cisgender woman. The authors also recognize the value of deliberately engaging with positionality statements at all levels of the TWC process. They plan to build this engagement into an introductory practice between participants, which could help illuminate what they "know," as informed by their lived experiences, while also opening up opportunities to understand better how these positionalities inform what both participants and researchers hope to gain from the forum outside of research-based knowledge production (Rose, 1997, pp. 308-309).

Alongside a more deliberate evocation of positionality, the authors will also fold into TWC design activities that promote reflexive activity. These may include asking participants to reflect on an opening question asking what brought them there or a having participants engage in an activity to reflect on their intersecting experiences of social difference and privilege. Before the forum, the authors will engage table hosts in more extensive training that primes them to reflect on whose ideas and discoveries from table discussions they might privilege over others. For instance, hosts who are librarians/paraprofessionals may be asked: What does it mean to be neutral? Who gets to be neutral? Who is served by this neutral stance? From a data collection perspective, the authors will ask participants to fill out a pre-TWC questionnaire, which has them express which of their identities are salient to informing their lived experience. The authors will ask table hosts to record who is at each table for each round so that they can match these identities with discussion topics and critically analyze how the identities of those at the table shaped conversational topics. Finally, the lead researchers will take detailed observational notes during the forum to note non-verbal and non-textual forms of participation.

\section{Conclusion}


TWC can offer compelling methodological insights into community-centric LIS research and practice. However, its promises may not reflect reality, as evidenced in prior critique (Aldred, 2009; Lorenzetti et al., 2016) and by the authors' application of the methodology to a case study. TWC assumes that community conversation can occur in a vacuum isolated from external influence (Aldred, 2009). This assumption is problematic because it omits the potential for the methodology to critically interrogate existing conditions permitting oppression of particular communities or participants (Lorenzetti et al., 2016). However, the authors have advanced potential interventions informed by their findings to align TWC with "strong" forms of constructivism in ways that restore power to participants.

\section{References}

Abildgaard, J. S., Løvseth, L. T., Ala-laurinaho, A., \& Nielsen, K. (2018). Forms of participation : The development and application of a conceptual model of participation in work environment interventions. Economic and Industrial Democracy, 1-24. https://doi.org/10.1177/0143831X17743576

Aldred, R. (2009). From community participation to organizational therapy? World Cafe and Appreciative Inquiry as research methods. Community Development Journal, 46(1), 57-71. https://doi.org/10.1093/cdj/bsp039

Arao, B., \& Clemens, K. (2013). From safe spaces to brave spaces: A new way to frame dialogue around diversity and social justice. In The Art of Effective Facilitation (pp. 135-150).

Sterling, VA: Stylus Publishing, LLC.

Brown, J. (2001). The World Cafe: Living knowledge through conversations that matter. Santa Barbara, CA: (Unpublished doctoral dissertation). Fielding Graduate University.

Brown, J., \& Isaacs, D. (2005). Creating hospitable spaces: The World Cafe. San Francisco, CA: 


\section{Berrett-Koehler.}

Bushe, G. R., \& Marshak, R. J. (2009). Revisioning organization development: Diagnostic and dialogic premises and patterns of practice. The Journal of Applied Behavioral Science, 45(3), 348-368.

Bushe, G. R., \& Paranjpey, N. (2015). Comparing the generativity of problem solving and appreciative inquiry: A field experiment. The Journal of Applied Behavioral Science, 51(3), 309-355. https://doi.org/10.1177/0021886314562001

Carson, L. (2011). Designing a public conversation using the World Café method. Social Alternatives, 30(1), 10-14.

Chatman, E. A. (1996). The impoverished life-world of outsiders. Journal of The American Society for Information Science, 47(3), 193-206. https://doi.org/10.1002/(SICI)10974571(199603)47:3<193::AID-ASI3>3.3.CO;2-M

Chatman, E. A. (1999). A theory of life in the round. Journal of the American Society for Information Science, 50(3), 207-217. https://doi.org/10.1002/(SICI)10974571(1999)50:3<207::AID-ASI3>3.3.CO;2-8

Craig, G. (2007). Community capacity-building: something old, something new . . ? Critical Social Policy, 27, 335-359.

Dervin, B. (1999). On studying information seeking methodologically: the implications of connecting metatheory to method. Information Processing \& Management, 35(6), 727-750. https://doi.org/10.1016/S0306-4573(99)00023-0

Drabinski, E. (2013). Queering the catalog: Queer theory and the politics of correction. Library Quarterly: Information, Community, Policy, 83(2), 94-111. https://doi.org/http://www.jstor.org/stable/10.1086/669547 
Durrance, J. C. (2001). The vital role of librarians in creating informaiton communities:

Strategies for success. Library Administration \& Management, 15(3), 161-168.

Estacio, E. V., \& Karic, T. (2016). The World Café : An innovative method to facilitate reflections on internationalisation in higher education. Journal of Further and Higher Education, 40(6), 731-745. https://doi.org/10.1080/0309877X.2015.1014315

Fisher, K. E., \& Bishop, A. P. (2015). Information communities: Defining the focus of information service. In S. Hirsh (Ed.), Information Services Today (1st ed., pp. 20-26). London, UK: Rowman \& Littlefield.

Fisher, K. E., Durrance, J. C., \& Hinton, M. B. (2004). Information grounds and the use of needbased services by immigrants in Queens, New York: A context-based, outcome evaluation approach. Journal of the American Society for Information Science and Technology, 55(8), 754-766. https://doi.org/10.1002/asi.20019

Fouche, C., \& Light, G. (2010). An invitation to dialogue. Qualitative Social Work, 10(1), 2848. https://doi.org/10.1177/1473325010376016

Freire, P. (1970). Pedagogy of the oppressed. New York, NY: Seabury Press.

Frohmann, B. (1992). The power of images: A discourse analysis of the cognitive viewpoint. Journal of Documentation, 48(4), 365-386. https://doi.org/10.1108/eb026904

Gahagan, J., \& Colpitts, E. (2017). Understanding and measuring LGBTQ pathways to health: A scoping review of strengths-based health promotion approaches in LGBTQ health research. Journal of Homosexuality, 64(1), 95-121. https://doi.org/10.1080/00918369.2016.1172893

Gibson, A. N., Chancellor, R. L., Cooke, N. A., Dahlen, S. P., Lee, S. A., \& Shorish, Y. L. (2017). Libraries on the frontlines: Neutrality and social justice. Equality, Diversity and Inclusion, 36(8), 751-766. https://doi.org/10.1108/EDI-11-2016-0100 
Gibson, A. N., \& Martin, J. D. (2019). Re-situating information poverty: Information marginalization and parents of individuals with disabilities. Journal of the Association for Information Science and Technology, 70(5), 476-487. https://doi.org/10.1002/asi.24128

Goldberg, M., Pasher, E., \& Levin-Sagi, M. (2006). Citizen participation in decision-making processes: Knowledge sharing in knowledge cities. Journal of Knowledge Management, 10, 92-98.

Greyson, D. (2017). Health information practices of young parents. Journal of Documentation, 73(5), 778-802. https://doi.org/10.1108/JD-07-2016-0089

Hillary, G. A. (1995). Definitions of community: Areas of agreement. Rural Sociology, 20, 111123.

Institute for Museum and Library Services. (n.d.). Community catalyst initatiative. Retrieved March 9, 2020, from https://www.imls.gov/our-work/community-catalyst-initiative Jaeger, P. T., \& Burnett, G. (2010). Information worlds: Behavior, technology, and social context in the age of the Internet. New York, NY: Routledge.

Jorgenson, J., \& Steier, F. (2013). Frames, framing, and designed conversational processes:

Lessons from the World Café. The Journal of Applied Behavioral Science, 49(3), 388-405. https://doi.org/10.1177/0021886313484511

Julien, H. (1999). Where to from here? Results of an empirical study and user-centered implications for system design. In T. D. Wilson \& D. K. Allen (Eds.), Exploring the Contexts of Information Behavior (pp. 586-596). London, UK: Taylor Graham Publishing.

Kitzie, V. (2019). "That looks like me or something i can do": Affordances and constraints in the online identity work of US LGBTQ+ millennials. Journal of the American Society for Information Science. https://doi.org/https://doi.org/10.1002/asi.24217 
Lankes, R. D., Silverstein, J., \& Nicholson, S. (2007). Participatory networks: The library as conversation. Information Technology and Libraries, 26(4), 17-33.

Lloyd, A., Anne Kennan, M., Thompson, K. M., \& Qayyum, A. (2013). Connecting with new information landscapes: information literacy practices of refugees. Journal of Documentation, 69(1), 121-144. https://doi.org/10.1108/00220411311295351

Lorenzetti, L. A., Azulai, A., \& Walsh, C. A. (2016). Addressing power in conversation: Enhancing the transformative learning capacities of the World Cafe. Journal of Transformative Education, 14(3), 200-219. https://doi.org/10.1177/1541344616634889

Nielsen, K., \& Randall, R. (2012). The importance of employee participation and perceptions of changes in procedures in a teamworking intervention. Work \& Stress: An International Journal of Work, Health \& Organisations, 26(2), 91-111. https://doi.org/10.1080/02678373.2012.682721

Noonan, E. J., Sawning, S., Combs, R., Weingartner, L. A., Martin, L. J., Jones, V. F., \& Holthouser, A. (2018). Engaging the transgender community to improve medical education and prioritize healthcare initiatives. Teaching and Learning in Medicine, 30(2), 119-132. https://doi.org/10.1080/10401334.2017.1365718

Ocepek, M. G. (2017). Bringing out the everyday in everyday information behavior. Journal of Documentation, 73(6), 1149-1166. https://doi.org/10.1108/JD-10-2016-0119

Olsson, M. (2005). Beyond 'needy' individuals: Conceptualizing information behavior. In Proceedings of the Association for Information Science and Technology. https://doi.org/10.1002/meet.1450420161

Reason, P., \& Bradbury, H. (2001). Introduction: Inquiry and participation in search of a world worthy of human participation. In P. Reason \& H. Bradbury (Eds.), Handbook of action 
research: Participative inquiry and practice (pp. 1-14). Thousand Oaks, CA: SAGE Publications, Inc.

Savolainen, R. (2008). Everyday information practices: A social phenomenological perspective. Lanham, MD: The Scarecrow Press, Inc.

Slocum, N. (2003). Participatory methods toolkit: A practitioner's manual. King Baudouin Foundation and the Flemish Institute for Science and Technology Assessment (viWTA).

Steier, F., Brown, J., \& Mesquita da Silva, F. (2015). The World Café in action research settings. In P. Reason \& H. Bradbury (Eds.), The SAGE Handbook of Action Research (pp. 211219). Thousand Oaks, CA: SAGE Publications, Inc.

Tafvelin, S., Schwarz, U. V. T., \& Nielsen, K. (2019). Employees ' and line managers ' active involvement in participatory organizational interventions : Examining direct, reversed, and reciprocal effects on well-being. Stress and Health, 35, 69-80. https://doi.org/10.1002/smi.2841

Terry, J., Raithby, M., Cutter, J., \& Murphy, F. (2015). A menu for learning : a World Café approach for user involvement and inter-professional learning on mental health. Social Work Education: The International Journal, 34(4), 437-458. https://doi.org/10.1080/02615479.2015.1031651

Thunberg, O. A. (2011). World cafes and dialog seminars as processes for reflective learning in organizations. Reflective Practice: International and Multidisciplinary Perspectives, 12, $319-333$.

van der Haar, D., \& Hosking, D. M. (2004). Evaluating Appreciative Inquiry: a relational constructionist perspective. Human Relations, 57(8), 1017-1036.

Westbrook, L. (2009). Crisis information concerns: Information needs of domestic violence 
survivors. Information Processing \& Management, 45(1), 98-114.

https://doi.org/10.1016/j.ipm.2008.05.005 